\title{
OUTCOMES OF EARLY ENDOSCOPIC REALIGNMENT OF POST-TRAUMATIC COMPLETE POSTERIOR URETHRAL RUPTURE
}

\author{
RAHMAN MM ${ }^{1}$, CHOWDHURY SA ${ }^{2}$, RAHMAN MM ${ }^{3}$, MIAH $\mathrm{JI}^{4}$, GHOSH KC ${ }^{5}$, RAHMAN NM ${ }^{6}$, \\ RAHMAN MM ${ }^{7}$, AHMED TA ${ }^{8}$, KARMAKER U ${ }^{9}, \mathrm{KHAN} \mathrm{SH}^{10}$
}

\begin{abstract}
:
Objective: To report the experience with patients treated by early endoscopic realignment of complete post-traumatic rupture urethra.

Methods: The cross sectional study included 30 patients in Dhaka Medical College Hospital and different private hospitals in Dhaka, Bangladesh, between April 2010 and March 2014 with post traumatic complete posterior urethral disruption. Pre-operative retrograde urethrography (RGU), micturition cysto urethrography (MCU) and ultrasonography (USG) of abdomen were performed to identify and to evaluate the Urethral defect length, the bladder neck competence, the prostate position and extend of pelvic hematoma. In second week after trauma, antegrade and retro-grade urethroscopy were performed to identify both urethral ends and insert a catheter. Before removal of catheter, Patients were followed up by pericatheter urethrogram after 4 weeks completed postoperative period. If extravasation seen, catheter was again maintained for another 2 weeks. Follow up was done by abdominal ultrasound and uroflowmetry 3 monthly up to 6 months and 6 monthly thereafter. RGU and MCU were performed 8 weeks after removal of catheter. Urinary continence and post-operative erectile dysfunction were assessed by direct patient interview.
\end{abstract}

Results: 30 patients in the age group 18-60 years (mean 36 years) were treated. Patients were followed up for 12 to 36 months. Complete healing of the urethra occurred in 10 patients. Passable urethral stricture developed in 12 patients. Complete urethral obstruction occurred in 8 patients.

Conclusion: Early endoscopic realignment for complete posterior urethral rupture is a feasible technique with no or minimal intra-operative complications. The technique is successful as the definite line of therapy in reasonable number of patients and it is seems to be effective Intervention for the prevention of inevitable urethral stricture formation.

J Dhaka Med Coll. 2015; 24(2) : 136-140.

\section{Introduction:}

Posterior urethral injury secondary to blunt trauma occurs in $5-10 \%$ of men who sustain pelvic fractures ${ }^{1,2}$. These injuries are associated with considerable morbidity, including urinary incontinence, erectile dysfunction and urethral strictures. These complications can lead to chronic disability,

1. Dr. Md. Mizanur Rahman, Associate Professor, Department of Urology, Dhaka Medical College, Dhaka.

2. Dr. Md. Shafiqul Alam Chowdhury, Associate Professor, Department of Urology, Dhaka Medical College, Dhaka.

3. Dr. Md. Mostafizur Rahman, Registrar, Department of Urology, Khwaja Yunus Ali Medical College Hospital, Sirajganj.

4. Prof. Md. Johirul Islam Miah, Professor \& Principal, Faridpur Diabetic Medical College, Faridpur.

5. Dr. Kartik Chandra Ghosh, HMO, Department of Urology, Dhaka Medical College, Dhaka.

6. Dr. Md. Nazmul Islam, Residential Surgeon, Department of Urology, Dhaka Medical College, Dhaka.

7. Dr. Md. Mostafizur Rahman, Assistant Professor, Department of Urology, Dhaka Medical College, Dhaka.

8. Dr.Tanvir Ahmed Chowdhury, In-door Medical Officer, Department of Urology, Dhaka Medical College, Dhaka.

9. Dr. Uttam Karmaker, Assistant Professor, Department of Urology, Dhaka Medical College, Dhaka.

10. Dr. Md. Shamim Hossain Khan, Assistant Professor, Holy Family Red Crescent Medical College, Dhaka. Correspondence: Dr. Md. Mizanur Rahman, Associate Professor, Department of Urology, Dhaka Medical College, Dhaka. 
resulting in long-term emotional and physical distress as well as significant financial loss.

The initial management of these devastating injuries involves early endoscopic realignment or placement of a suprapubic cystostomy tube followed by delayed urethroplasty. The cited advantages of early endoscopic realignment include an earlier return to voiding, the possibility of no future operative interventions, and if a urethral stricture develops early endoscopic relignment may better align the distracted urethral segments during formal urethroplasty ${ }^{3}$.

According to recent guideline partial tears of the posterior urethra should be managed with a suprapubic or urethral catheter. Urethrography should be performed at two weeks interval until healing has occurred. Partial tears may heal without significant scarring or obstruction if managed by diversion alone. Residual or subsequent stricture should be managed with urethral dilatation or optical urethrotomy if short and flimsy, and with anastomotic urethroplasty if dense or long.

Complete ruptures of the posterior urethra should be managed with a suprapubic catheter. There is still controversy between those supporting early intervention to realign the urethra and drain the pelvic haematoma and those supporting initial suprapubic cystostomy alone with delayed repair of the ensuing urethral defect 4 .

Acute treatment options include: 1. Primary endoscopic realignment; usually performed during the first $10 \mathrm{~d}$ after the injury. 2 . Immediate open urethroplasty; however, this is experimental and therefore not indicated ${ }^{1}$.

Our primary aim was to analyze the success of early endoscopic realignment after blunt pelvic fracture associated urethral injury in a subset of consecutive patients who were treated from initial injury to potential urethral reconstruction at our hospital and clinic. A secondary aim was to assess incontinence and erectile dysfunction during follow up clinic appointments.

\section{Methods:}

The cross sectional study was done in Dhaka Medical College Hospital and different private hospitals in Dhaka, Bangladesh, between April 2010 and March 2014. A total of 30 patients between 18 and 60 years of age presented with traumatic posterior urethral disruptions with associated pelvic fractures and/or diastasis pubis. The mechanism of injury in all patients was blunt trauma occurred by road traffic accident or other crush injury. Posterior urethral injury associated with tear of the bladder neck, rectum or vagina was excluded from this study. Diagnosis of urethral injury was made on the basis of retrograde urethrogram. Initial urologic management consisted of suprapubic tube insertion at the time of presentation. The timing of endoscopic realignment varied from 10 to 15 days after injury, depending on the overall stability of the patient. Before endoscopic realignment the condition was assessed by retrograde and or voiding urethrography. Patients in whom the bladder neck and prostatic urethra could not be visualized underwent repeat retrograde urethrography with ante-grade placement of a sound or cystoscope via regional anesthesia.

Urine cultures and appropriate intravenous antibiotics were started before the procedure. Realignment was performed under regional or general endotracheal anesthesia and either in a dorsal lithotomy or modiûed lithotomy position. Positioning was dictated by the extent of the pelvic fractures and lower extremity and lumbar spinal fractures. It was done with or without the help of fluoroscopic guidance. The suprapubic catheter was removed after passing a 0.038-in. guide wire. The suprapubic tract was dilated up to $24 \mathrm{~F}$, using Amplatz dilators and the Amplatz sheath was used as a conduit to pass a rigid $20 \mathrm{~F}$ cystoscope in an antegrade fashion to the bladder neck. Second rigid or $17 \mathrm{~F}$ ûexible cystoscope was passed in a retrograde fashion if necessary. A ûexible 0.038-in. guide wire was passed from above, grasped using the cystoscope, and pulled through distally. A Foley bi-channel catheter (of which tip was cut by 
scissor) was passed over the wire, and the wire was removed. Pericatheter urethrogram was performed after four weeks. If extravasation of of contrast was appreciated, the catheter remainted for another 2 weeks, and retrograde pericatheter urethrogram was repeated. Follow up was abdominal ultrasound and uroflowmetry 3 monthly up to 6 months and 6 monthly thereafter. RGU and MCU were performed 8 weeks after removal of catheter. Urinary continence and post-operative erectile dysfunction were assessed by direct patient interview.

\section{Results:}

Thirty patients in the age group 18-60 (mean 36 years) were treated. The mean follow-up was an average of 23 months (12-36 months).

A total of 10 patients (33.33\%) had no radiographic evidence or symptoms of urethral strictures and they required no further urological procedures. Passable urethral stricture developed in 12 patients (40\%). Complete urethral obstruction occurred in 8 patients $(26.67 \%)$.

Following realignment 24 of 30 patients (80\%) reported normal erections, while 4 (13.3\%) reported decreased quality of erection and none of 4 patients required treatment for erectile dysfunction. Of the 2 of 30 patients $(6.67 \%)$ who were unable to obtain erections suitable for intercourse.

Of the 30 patients $28(93.33 \%)$ reported normal urinary control, while $2(6.67 \%)$ reported mild post-injury and realignment stress urinary incontinence not requiring protective padding or treatment. Urinary sphincter exercises were satisfactory in the latter 2 patients.

The result of our 30 patients treated with endoscopic urethral realignment is summarized in Table-I. The main etiology of injury was road traffic accident. Mean time of injury to early endoscopic realignment was 11 days (10-15 days). Mean duration of urethral catherization after endoscopic realignment was days (range 28-42 days). Based on this approach overall success rate was $33.33 \%$ with a mean follow up of 23 months.
Table-I

Summary of the results of early endoscopic realignment of post-traumatic complete posterior urethral rupture $(n=30)$

\begin{tabular}{lcc}
\hline Variables & $\begin{array}{c}\text { No. of } \\
\text { patients }\end{array}$ & Percentage \\
\hline Case success & & \\
No evidence of stricture & 10 & $33.33 \%$ \\
Passable stricture & 12 & $40 \%$ \\
$\begin{array}{l}\text { Complete stricture } \\
\text { Erectile dysfunction }\end{array}$ & 8 & $26.67 \%$ \\
$\begin{array}{l}\text { Normal erection } \\
\text { Decrease quality of }\end{array}$ & 24 & $60 \%$ \\
erection & 4 & $13.33 \%$ \\
$\begin{array}{l}\text { Complete erectile } \\
\text { dysfunction }\end{array}$ & 2 & $6.67 \%$ \\
$\begin{array}{l}\text { Urinary continence } \\
\text { Normal control }\end{array}$ & 28 & $93.33 \%$ \\
Stress incontinence & 2 & $6.67 \%$ \\
Incontinence & 0 & $00 \%$ \\
\hline
\end{tabular}

\section{Discussion:}

Treatment of a traumatic posterior urethral stricture remains a difficult challenge. The mechanism of this injury involves significant shearing forces at the prostate-membranous junction, resulting in avulsion of the urethra from the fixed urogenital diaphragm. After diagnosing this type of injury, the goal of treatment should be directed toward achieving urethral continuity while minimizing the risk of complications. In the last 80 years debate has been ongoing in the urological and trauma literature regarding the safest method of treating these potentially catastrophic injuries. Conventional therapy for such strictures has involved extensive perineal, trans pubic or combined urethroplasties, which were associated with prolonged hospital stays of 11 to 37 days, operative blood loss of 700 to 5,500 cc and impotence in 20 to $30 \%$ of cases, recurrent stenosis in 40 to $55 \%$ and need for a repeat procedure in 57 to $66 \%$. In the last 30 years practice patterns have returned to favor early urethral realignment via endourological methods ${ }^{3,5,6,8,9}$. Modern techniques of early endoscopic realignment were introduced in the late 1980s. These techniques evolved into a combination of transurethral and transvesical endourological procedures in conjunction with 
ûuoroscopy. This technique is postulated to avoid further damage to erectile function since there is no manipulation of the periprostatic tissues and, thus, no additional trauma to the neurovascular bundles ${ }^{3,6}$. The problem of postrealignment incontinence was minimal in our study. Only 2 of 30 patients $(6.67 \%)$ reported any leakage of urine, and in both it was mild and needed no treatment. These results compare favorably with prior results of delayed repair. By strict definition, 20 of our 30 patients $(66.67 \%)$ followed had postrealignment strictures; however, 12 of those 20 were treated easily. The severity of the strictures and their effect on quality of life were minimal.

Regarding impotence following posterior urethral disruptions, previous analyses of primary realignment have reported a high incidence of impotence ${ }^{12-14}$. Conversely, in numerous studies it was concluded that impotence is due to the traumatic nature of the pelvic fracture and not to the realignment procedure. It appears that the complication of impotence in patients who undergo primary realignment most likely results from the combination of the nature of the injury and excessive manipulation of the already grossly traumatized tissue. Therefore, it is believed that the goal and success of immediate primary realignment lie in the ability to perform the procedure in as timely a fashion as possible with minimal disruption to the already traumatized periprostatic tissue. Only 2 of our patients $(6.67 \%)$ had sufficient erectile dysfunction that required treatment. These results compare favorably to those of others reporting on delayed urethral repair ${ }^{15-20}$.

\section{Conclusion:}

Although the number of patients in our study is small and long-term follow-up is awaited, we believe that the early endoscopic realignment can be useful and should be considered initially in patients with a post-traumatic complete posterior urethral rupture.

\section{References:}

1. Martínez-Piñeiro L, Djakovic N, Plas E, Mor Y, Santucci RA, Serafetinidis E, Turkeri LN, et al. EAU guidelines on urethral trauma. Eur Urol 2010; 57(5): 791-803.

2. Elliott DS, Barrett DM. Long-term followup and evaluation of primary realignment of posterior urethral disruptions. J Urol 1997; 157: 814-6.

3. Leddy LS, Vanni AJ, Wessells H, Voelzke BB. Outcomes of endoscopic realignment of pelvic fracture associated urethral injuries at a level 1 trauma center. J Urol 2012; 188: 174-8.

4. Jepson BR, Boullier JA, Moore RG, Parra RO. Traumatic posterior urethral injury and early Primary endoscopic realignment: Evaluation of long-term follow-up. Urology 1999; 53(6): 1205-7.

5. McRoberts JW, Ragde H. The severed canine posterior urethra: a study of two distinct methods of repair. J Urol 1970; 104: 724.

6. Koraitim MM. Pelvic fracture urethral injuries: The unresolved controversy. J Urol 1999; 161: 1433.

7. Mouraviev VB, Coburn M, Santucci RA. The treatment of posterior urethral disruption associated with pelvic fractures: comparative experience of early realignment versus delayed urethroplasty. J Urol 2005; 173: 873.

8. Ragde H, McInnes GF. Transpubic repair of the severed prostatomembranous urethra. J Urol 1969; 101: 335.

9. Pokorny M, Pontes JE, Pierce JM Jr. Urological injuries associated with pelvic trauma. J Urol 1979; 121: 455.

10. Ku JH, Kim ME, Jeon YS et al. Management of bulbous urethral disruption by blunt external trauma: the sooner, the better? Urology 2002; 60: 579 .

11. Clark SS, Prudencio RF. Lower urinary tract injuries associated with pelvic fractures: diagnosis and management. Surg Clin North Am 1972; 52: 183.

12. Webster GD, Mathes GL, Selli C. Prostatomembranous urethral injuries: a review of the literature and a rational approach to their management. $\mathrm{J}$ Urol 1983; 130: 898-902.

13. Dixon CM. Diagnosis and acute management of posterior urethral disruptions. In: McAninch JW, ed. Traumatic and reconstructive urology. Philadelphia: WB Saunders; 1996: p.347-55.

14. Coffield KS, Weems WL. Experience with management of posterior urethral injury associated with pelvic fracture. J Urol 1977; 117: 722-4. 
15. Venn SN, Mundy AR. Trauma and reconstruction: The immediate management of major trauma to the urinary tract. Eur Urol 1998; 33: 1-8.

16. Corriere JN. 1-Stage delayed bulboprostatic anastomotic repair of posterior urethral rupture: 60 patients with 1-year followup. J Urol 2001; 165: 404-7.

17. Muhlbauer S, Bard RH. Early definitive urologic management of patient with crush pelvic trauma and deep perineal laceration. Urology 1980; 15: 56-9.
18. Webster GD. Impotence following delayed repair of prostatomembranous urethral disruption (editorial comment). J Urol 1990; 144: 678.

19. Koraitim MM. The lessons of 145 posttraumatic posterior urethral strictures treated in 17 years. J Urol 1995; 153: 63-6.

20. Podesta ML. Use of the perineal and perinealabdominal (transpubic) approach for delayed management of pelvic fracture urethral obliterative strictures in children: long-term outcome. J Urol 1998; 160: 160-4. 